\title{
PASTEJO E ADUB AÇÃO NITROGENADA SOBRE OS ATRIBUTOS FÍSICOS DO SOLO EM SISTEMA DE INTEGRAÇÃO LAVOURA-PECUÁRIA
}

Doi:http://dx.doi.org/10.1590/1809-4430-Eng.Agric.v35n6p 1019-1031/2015

\section{VERUSCHKA R. M. ANDREOLLA ${ }^{1}$, ANÍBAL DE MORAES ${ }^{2}$, AMADEU BONA FILHO ${ }^{3}$, DECIO L. CARDOSO ${ }^{4}$, EDILSON B. DE OLIVEIRA ${ }^{5}$, ANDREIA K. BONINI ${ }^{6}$}

\begin{abstract}
RESUMO: O sistema de integração lavoura-pecuária (SILP) é uma alternativa que vem atraindo grande interesse dos agricultores nas regiões produtoras de grãos, devido ao suporte à pecuária por meio da produção de alimento, além de melhoria nas propriedades físicas do solo. O objetivo deste trabalho foi avaliar o efeito do pastejo e da adubação nitrogenada em atributos físicos do solo e na produtividade da cultura do milho, em um sistema de integração lavoura-pecuária. $\mathrm{O}$ delineamento foi em blocos ao acaso, com parcelas subdivididas, sendo as parcelas as doses de nitrogênio, e as subparcelas, a presença e ausência de pastejo. Foram utilizadas três repetições por tratamento. Os tratamentos foram doses de nitrogênio de $0 ; 75 ; 150$ e $225 \mathrm{~kg} \mathrm{ha}^{-1}$ aplicados na pastagem de azevém (Lolium multiflorum Lam.) e aveia-branca (Avena sativa Lam.) no inverno. Posteriormente à pastagem, foi implantada a cultura do milho (Zea mays Lam.) no verão. O pastejo com controle da taxa de lotação animal de ovinos e manutenção da massa de forragem consorciada com aveia e azevém não alterou a densidade, a macroporosidade, a microporosidade e a porosidade total no Latossolo Bruno. O pastejo nas áreas que receberam adubação nitrogenada na pastagem, não prejudicou a produtividade da cultura do milho. A adubação nitrogenada da pastagem de inverno, igual ou superior a $150 \mathrm{~kg} \mathrm{~N} \mathrm{ha}^{-1}$, garante elevada produtividade da cultura do milho na ausência da aplicação de N.
\end{abstract}

PALAVRAS-CHAVE: sistemas integrados, compactação do solo, aze vém, aveia, pastagem.

\section{EFFECTS OF GRAZING AND NITROGEN FERTILIZATION ON SOIL PHYSICAL PROPERTIES IN A CROP-LIVESTOCK FARMING SYSTEM}

\begin{abstract}
Grain farmers have seen integrated crop-livestock systems (ICLS) as an alternative of great interest by providing cattle food supply, as well as improvement of the phisical properties of soil. This study aimed at evaluating the effect of grazing and nitrogen levels on soil physical properties and on corn yield in an integrated crop-livestock farming. The experimental design was a randomized complete block design with a split plot arrangement of treatments and three replications per treatment; nitrogen doses were the main plots, and grazing presence or absence were the subplots. We applied four doses of nitrogen $\left(0,75,150\right.$, and $\left.225 \mathrm{~kg} \mathrm{ha}^{-1}\right)$ in soils grown with ryegrass (Lolium multiflorum Lam.) and oat (Avena sativa Lam.) during winter. After the grazing period, the area was planted with corn (Zea mays Lam.) within summer. Sheep grazing with stocking rate control and herbage mass maintenance using oats and ryegrasses did not change soil density, macro, micro and total porosity in a Bruno Latosol (Oxisol). Grazing in nitrogen-fertilized areas did not impair corn yield. Previous nitrogen fertilization in winter grazing, in amounts equal to or higher than $150 \mathrm{~kg} \mathrm{~N}$ ha-1, ensures high corn yields in the absence of $\mathrm{N}$ applications.
\end{abstract}

KEYWORDS: integrated systems, soil compaction, ryegrass, oat, grazing.

\footnotetext{
${ }^{1}$ Eng $^{\text {a }}$ Agrônoma, Pós-Doutora em Agronomia (Produção Vegetal), Departamento de Fitotecnia e Fitossanitarismo, UFPR/Curitiba - -PR, Fone: (0xx45) 9971 4766,vandreolla @y ahoo.com.br

${ }^{2}$ Eng $^{\circ}$ A grônomo, Professor Doutor, Departamento de Fitotecnia e Fitossanitarismo/UFPR, Curitiba - PR, co-orientador, anibalm@ufpr.br

${ }^{3}$ Médico Veterinário, Professor Doutor, Departamento de Fitotecnia e Fitossanitarismo/UFPR, Curitiba-PR, orientador, abonafilho@gmail.com

${ }^{4}$ Eng $^{\circ}$ Civil, Professor Doutor da Universidade Estadual do Oeste do Paraná-UNIOESTE, Cascavel-PR, decio.cardoso@unioeste.br

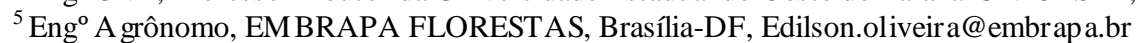

${ }^{6}$ Bióloga, Mestre em Engenharia Agrícola, UNIOESTE- Cascavel-PR,akbonini@y ahoo.com.br

Recebido pelo Conselho Editorial em: 25-10-2013
}

Aprovado pelo Conselho Editorial em: 27-5-2015 


\section{INTRODUÇÃO}

A implantação de sistema de integração lavoura-pecuária (SILP), em áreas de plantio direto, vem tornando-se expressiva em todo o Brasil, em virtude de ser uma alternativa de manejo que traz inúmeros benefícios. No entanto, pesquisas estão sendo realizadas para evidenciar a melhoria nas propriedades físicas, químicas e biológicas e consequentemente, na manutenção da estabilidade do sistema (CONTE et al., 2011).

A presença de animais na pastagem tem efeitos diretos e indiretos sobre a forragem e solo. A pressão aplicada pelo pisoteio dos animais tende a alterar o ambiente; no entanto, quando as pastagens são manejadas adequadamente, geralmente essa pressão é dissipada. Neste sistema, ocorre incremento do teor de matéria orgânica do solo e o desenvolvimento do sistema radicular fasciculado e agressivo das gramíneas das forrageiras auxiliam na estruturação do solo, bem como o aumento da disponibilidade de nutrientes que facilita a decomposição de substratos e influenciam os processos de mineralização/imobilização de nitrogênio (PETEAN et al., 2010; ROZANE et al., 2010).

A intensidade de pisoteio é determinante na compactação do solo sob integração lavourapecuária com aveia e azevém no inverno, no Sul do Brasil. Desta forma, a carga animal deve ser adequada à disponibilidade de forragem, para diminuir o impacto sobre as propriedades físicas do solo. Segundo ANDREOLLA et al. (2014) e PETEAN et al. (2009), o efeito do pisoteio animal sobre as propriedades físicas do solo é limitado às suas camadas mais superficiais, podendo ser temporário e reversível, quando a pastagem é manejada adequadamente.

O impacto do pisoteio animal sobre a qualidade do solo tem sido monitorado através do mensuramento das propriedades físicas do solo, com o intuito de realizar um manejo sustentável, diminuindo desta forma processos de compactação e densificação (SILVA et al., 2011; SANTOS et al., 2011).

De acordo com MOREIRA et al. (2012), as alterações nas propriedades físicas do solo devem-se a um conjunto de fatores como a textura do solo, altura e intensidade de pastejo, quantidade de resíduo vegetal da forragem e umidade do solo, que podem maximizar o efeito do pisoteio animal.

Neste contexto, dentre as culturas sucessoras ao período de pastejo, a do milho é a que demanda maior aplicação de nitrogênio $(\mathrm{N})$. Por essa razão, é a cultura que melhor responde à adubação nitrogenada da pastagem. Além do mais, a utilização de uma gramínea no período de verão é necessária, de forma a possibilitar a rotação de culturas, prática que é imprescindível para a sustentabilidade do sistema integração lavoura-pecuária, pois melhora a qualidade e a conservação do solo, reduz a incidência de insetos-praga, doenças e plantas daninhas, e aumenta a diversificação temporal da exploração econômica na propriedade rural (BALBINOT JÚNIOR et al., 2012; BALBINOT JÚNIOR et al., 2011a; SANDINI et al., 2011).

O objetivo deste trabalho foi avaliar o efeito do sistema de integração lavoura-pecuária em diferentes doses de $\mathrm{N}$, sobre os atributos físicos do solo e a produtividade da cultura do milho.

\section{MATERIAL E MÉTODOS}

O experimento foi conduzido na Universidade Estadual do Centro-Oeste (UNICENTRO), no município de Guarapuava (PR), Brasil, cujas coordenadas geográficas são $25^{\circ} 33^{\prime}$ latitude sul e $51^{\circ}$ 29' e longitude oeste.

O histórico diz respeito às culturas de inverno/verão sob sistema de plantio direto na área experimental de 2004 até a realização do experimento (Tabela 1). 
TABELA 1. Sequência de culturas cultivadas no período de 2004 a 2008. Crop sequence from 2004 to 2008.

\begin{tabular}{lc}
\hline \multicolumn{1}{c}{ Estação } & Culturas \\
\hline Inverno 2004 & Cereais \\
Verão2004/2005 & Soja (Glycine max) \\
Inverno 2005 & Pousio \\
Verão 2005/2006 & Milho (Zea mays) para silagem \\
Inverno 2006 & Aze vém (início do experimento) \\
Verão 2006/2007 & Feijão (Phaseolus Vulgaris Lam.), \\
Inverno 2007 & Aze vém (Lolium multiflorum Lam) e aveia (Avena sativa Lam) \\
Verão 2007/2008 & Milho \\
\hline
\end{tabular}

Foi efetuado o balanço hídrico dos anos de 2007 e 2008 (Figura 1), que compreende o período de realização do experimento de forma a verificar a ocorrência de deficiência hídrica. A metodologia empregada foi a de THORNTHWAITE \& MATHER (1955), utilizando-se para cálculo de planilha eletrônica desenvolvida por ROLIM et al. (1998).
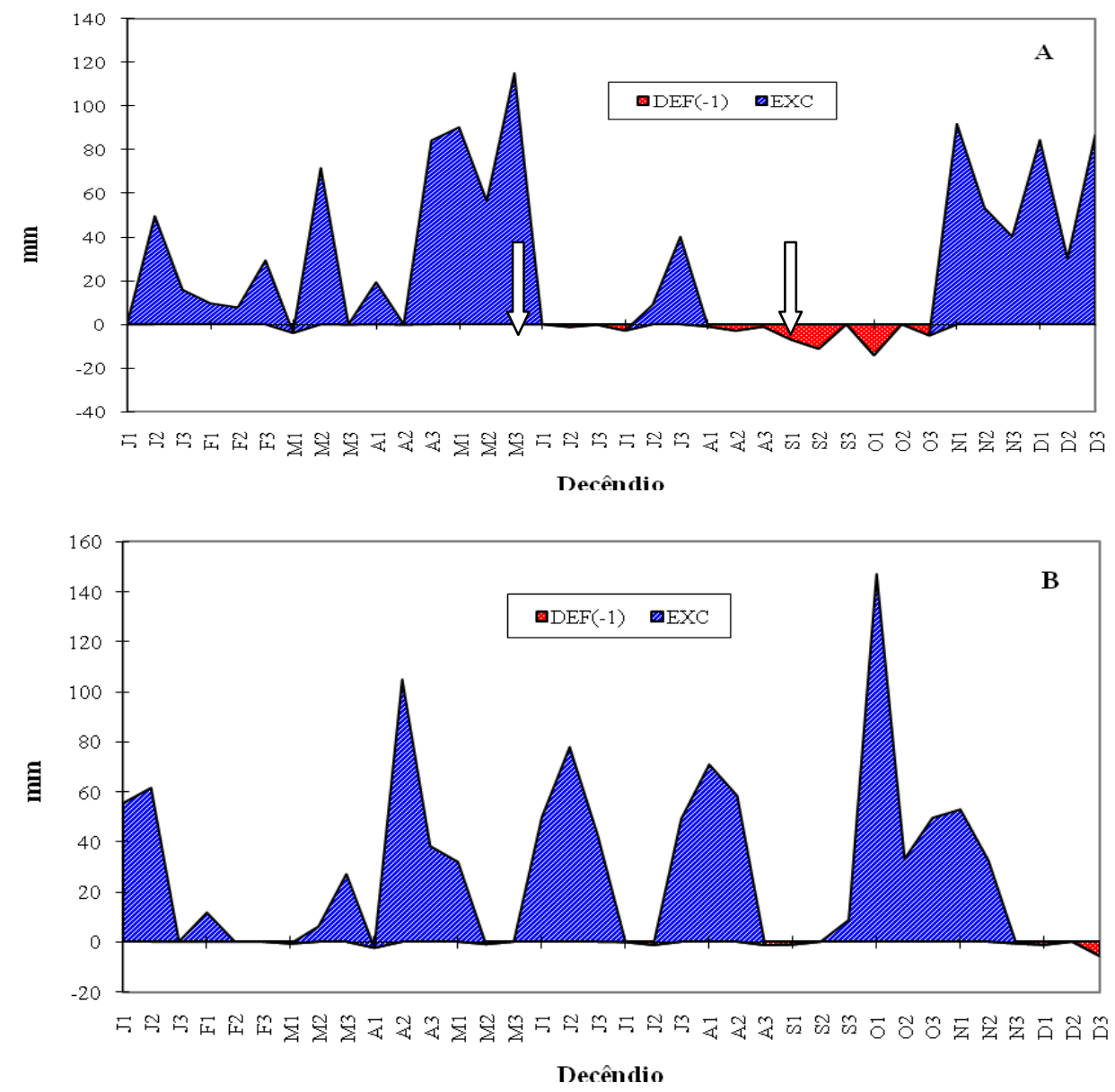

FIGURA 1. Balanço hídrico sequencial de cada intervalo de 10 dias, durante o ano de 2007 (A) e 2008 (B). Guarapuava - PR, 2008. As setas indicam o período de pastejo em 2008. Sequential water balance at each 10-day inte rval during the year of 2007 (A) and 2008 (B), in the state of Paraná, Brazil, 2008. The arrows indicate the grazing period in 2008.

Os dados de temperaturas $\left({ }^{\circ} \mathrm{C}\right)$ máxima, mínima e média, nos decêndios do mês de abril de 2007 até abril de 2008, constam na Figura 2. 


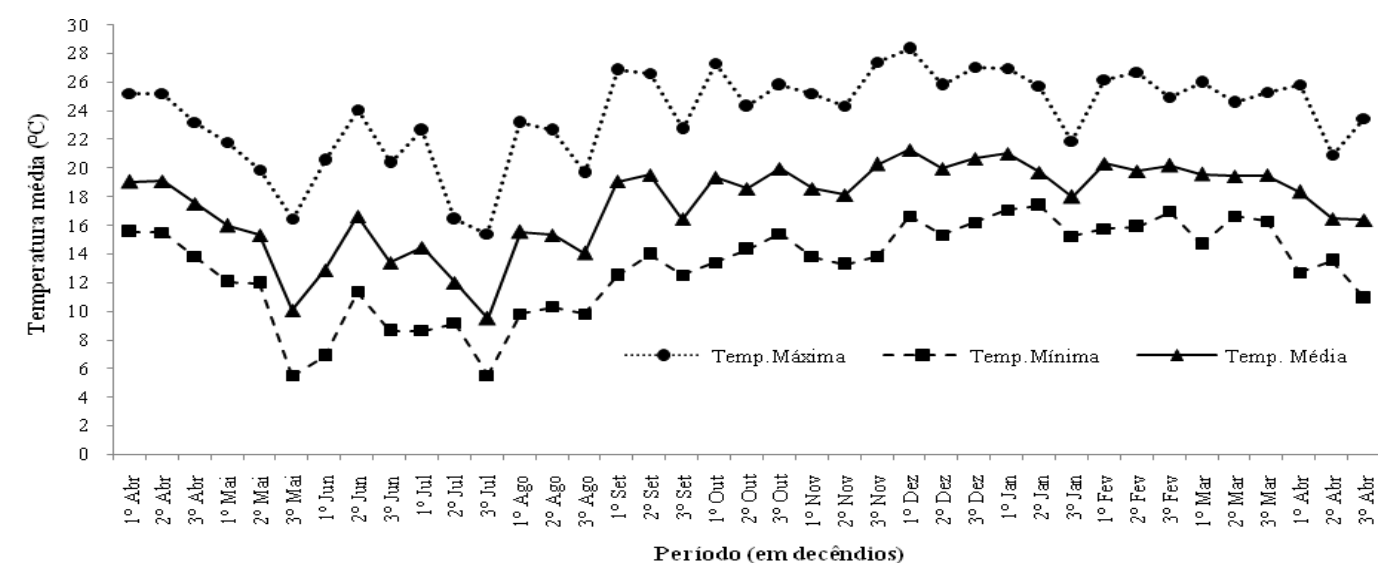

FIGURA 2. Temperaturas $\left({ }^{\circ} \mathrm{C}\right)$ máxima, mínima e média nos decêndios do mês de abril de 2007 até abril de 2008. Guarapuava - PR. *Temperatura média calculada de acordo com o INMET $\left(\right.$ Tmed $\left.=\left(\mathrm{T}_{9 \mathrm{~h}}+\mathrm{T}_{\max }+\mathrm{T}_{\min }+2 \times \mathrm{T}_{21 \mathrm{~h}}\right) / 5\right)$.

Maximum, minimum, and mean temperatures $\left({ }^{\circ} \mathrm{C}\right)$ in ten-day intervals from April 2007 up to April 2008 in Guarapuava, PR. *Mean te mperature calculated according to the INMET $\left(\mathbf{T}_{m}=\left(\mathbf{T}_{9 h}+\mathbf{T}_{\max }+\mathbf{T}_{\min }+2 \times \mathbf{T}_{21 h}\right) / 5\right)$.

Avaliou-se a granulometria do solo pelo método da pipeta, descrita por EMBRAPA (1997). O solo da área experimental foi classificado como Latossolo Bruno distroférrico típico (EMBRAPA, 2013). Para a análise química, procedeu-se à amostragem de solo nas camadas de $0-5 ; 5-10$ e 10 - 15 cm do perfil, antes da instalação do experimento, e os dados constam na Tabela 1.

TABELA 2. Parâmetros químicos do solo, caracterização granulométrica e densidade de partículas $\left(\mathrm{Mg} \mathrm{m}^{-3}\right)$, Guarapuava - PR, no ano de 2007, para diferentes profundidades. Soil chemical prope rties, particle size characterization and particle density $\left(\mathrm{Mg} \mathrm{m}^{-3}\right)$ at diffe rent depths (Guarapuava - PR, Brazil, 2007).

\begin{tabular}{|c|c|c|c|c|c|c|c|c|c|c|c|c|c|c|}
\hline $\begin{array}{c}\text { Camada } \\
(\mathrm{cm})\end{array}$ & $\begin{array}{c}\mathrm{pH} \\
\left(\mathrm{CaCl}_{2}\right) \\
\end{array}$ & $\mathrm{OM}$ & P & K & $\mathrm{Ca}$ & $\mathrm{Mg}$ & $\mathrm{Al}$ & $\mathrm{H}+\mathrm{Al}$ & CEC & V & Areia & Silte & Argila & Dp \\
\hline & & $\mathrm{g} \mathrm{dm}^{-}$ & $\operatorname{ggdn}$ & & & $\mathrm{cm}$ & $I_{c} \mathrm{dm}^{-}$ & & & $\%$ & & $\mathrm{~g} \mathrm{~kg}^{-1}$ & & $\mathrm{Mg} \mathrm{m}^{-3}$ \\
\hline-5 & 5.2 & 52.9 & 5.9 & 0.49 & 5.03 & 2.85 & 0.00 & 5.18 & 13.55 & 61.81 & 80.4 & 305.9 & 613.7 & 2,54 \\
\hline $5-10$ & 5.2 & 46.6 & 3.0 & 0.23 & 4.62 & 2.90 & 0.00 & 5.01 & 12.77 & 60.70 & 70.4 & 316.5 & 613.1 & 2,54 \\
\hline $10-15$ & 5.2 & 45.9 & 2.7 & 0.21 & 4.56 & 2.84 & 0.00 & 4.73 & 12.33 & 61.59 & 76.8 & 308.0 & 615.2 & 2,58 \\
\hline média & 5.2 & 48.5 & 3.8 & 0.31 & 4.74 & 2.86 & 0.00 & 4.98 & 12.88 & 61.37 & 75.9 & 310.2 & 613.9 & \\
\hline
\end{tabular}

O delineamento utilizado foi em blocos ao acaso, com parcelas subdivididas e três repetições. As parcelas foram constituídas pelas dosagens de nitrogênio com $0 ; 75 ; 150$ e $225 \mathrm{~kg} \mathrm{ha}^{-1}$, na integração de pastagem de azevém (Lolium multiflorum Lam.) e aveia (Avena Sativa Lam.) no inverno, com cultura do milho (Zea mays), no verão. As subparcelas foram com e sem pastejo.

A área experimental total compreendeu 3,1 ha, dos quais foram utilizados 2,6 ha, subdivididos em três blocos de 0,88 ha, sendo cada bloco dividido em 4 parcelas de 0,22 ha. Em cada parcela, foi isolada uma área de $96 \mathrm{~m}^{2}$, que permaneceu sem pastejo. O 0,5 ha restante foi utilizado para a manutenção dos animais reguladores enquanto não estavam no experimento. Os tratamentos corresponderam a quatro doses de nitrogênio $(\mathrm{N})$, na forma de ureia $(45 \% \mathrm{de} \mathrm{N})$, sendo: $0 \mathrm{~kg}$ de $\mathrm{N}$ $\mathrm{ha}^{-1} ; 75 \mathrm{~kg}$ de $\mathrm{N} \mathrm{ha}^{-1}$ de $\mathrm{N} ; 150 \mathrm{~kg}$ de $\mathrm{N} \mathrm{ha}^{-1}$; e $225 \mathrm{~kg} \mathrm{de} \mathrm{N} \mathrm{ha}^{-1}$ na pastagem.

A semeadura da forragem foi realizada em 15 de abril de 2007, no sistema de semeadura direta, tendo como cultura de verão antecessora o feijoeiro. Foram utilizados $80 \mathrm{~kg} \mathrm{ha}^{-1}$ de aveiabranca e $35 \mathrm{~kg} \mathrm{ha}^{-1}$ de aze vém, com espaçamento de $17 \mathrm{~cm}$ entre linhas. A emergência das plântulas ocorreu 8 dias após a semeadura. Como adubação de base, foram aplicados $250 \mathrm{~kg} \mathrm{ha}^{-1}$ do fertilizante formulado 00-25-25 (N, $\left.\mathrm{P}_{2} \mathrm{O}_{5}, \mathrm{~K}_{2} \mathrm{O}\right)$. Os tratamentos foram aplicados como adubação de cobertura, em dose única, 30 dias após a emergência (DAE). 
O pastejo ocorreu do dia 10 de junho de 2007 até o dia 28 de setembro de 2007, totalizando 110 dias de pastejo. Os animais utilizados eram cordeiros, da raça Ile de France, os quais permaneceram com suas mães até o dia 28 de julho, quando então foram desmamados. $\mathrm{O}$ sistema de pastejo utilizado foi o contínuo, com carga variável, objetivando manter a altura da pastagem entre 14 e 15 cm (MOOT \& LUCAS, 1952), seguindo recomendações de FREITAS (2003). Assim, os ajustes da lotação foram feitos periodicamente, em intervalos de 3 dias, considerando a relação entre a altura e a massa de forragem, segundo CARVALHO et al. (2001).

Foram utilizados 24 cordeiros-teste, machos e fềmeas, que permaneceram com suas mães durante 49 dias, quando então foram desmamados. O peso vivo médio inicial dos cordeiros era 9,5 $\mathrm{kg}$ e das matrizes de $47,8 \mathrm{~kg}$. Os animais foram distribuídos aleatoriamente nos tratamentos, de acordo com peso e sexo. Os animais reguladores, oriundos do mesmo rebanho, foram formados por animais das mesmas categorias dos testes.

A carga animal é uma variável dependente, pois leva em consideração o somatório do peso médio dos animais-teste e o peso médio dos animais reguladores, multiplicado pelo número de dias que permaneceram na unidade experimental. $\mathrm{O}$ valor encontrado foi dividido pelo número de dias de pastejo e expresso em quilograma de peso vivo por hectare $\left(\mathrm{kg} \mathrm{ha}^{-1}\right)$.

Logo após a retirada dos animais da pastagem (28-09-07), ou seja, 15 dias depois, foi realizada a dessecação da pastagem, com herbicida glyphosate $\left(900 \mathrm{~g} \mathrm{ha}^{-1}\right)$. Posteriormente, foi realizada a semeadura do híbrido de milho '30F53', efetuada no dia 24-10-07, em sistema de plantio direto, com espaçamento de 0,8 m entre linhas. A emergência das plântulas ocorreu oito dias após a semeadura.

$\mathrm{Na}$ adubação, o fósforo e o potássio foram aplicados a lanço, antes da semeadura, nas dosagens de $100 \mathrm{~kg} \mathrm{ha}^{-1}$ de $\mathrm{P}_{2} \mathrm{O}_{5}$ e $100 \mathrm{~kg} \mathrm{ha}^{-1}$ de $\mathrm{K}_{2} \mathrm{O}$, sendo as fontes o supertriplo e o cloreto de potássio, respectivamente. Nao foi aplicado $\mathrm{N}$ na semedadura do milho.

O controle das plantas daninhas, por ocasião da dessecação, foi complementado pela aplicação de atrazine $\left(3.500 \mathrm{~g} \mathrm{ha}^{-1}\right)$ mais óleo mineral $\left(0,5 \mathrm{~L} \mathrm{ha}^{-1}\right)$, em pós-emergência 2007). Não foi efetuado controle de insetos, pragas e doenças.

A produtividade do milho foi determinada em área útil de $8 \mathrm{~m}^{2}$ (2 linhas x $0,8 \mathrm{~m}$ x 5 metros) e, depois da correção de umidade para $14 \%$, o valor foi convertido para $\mathrm{kg} \mathrm{ha}^{-1}$, sendo a colheita do milho efetuad a em 15-04-2008.

As camadas de amostragem do solo foram $0-5 ; 5-10$ e $10-15 \mathrm{~cm}$, com duas repetições, nos períodos prédeterminados: Fase 1 - Após colheita do feijão e Pré-plantio da pastagem (30-032007); Fase 2 - Após pastejo dos animais (12-10-2007) e Fase 3 - Após colheita do milho (19-052008).

A densidade do solo (Ds) foi determinada pelo método do anel volumétrico, a porosidade total, a macroporosidade e a microporosidade foram determinadas pelo método da mesa de tensão (EMBRAPA, 1997).

Os resultados foram submetidos à análise de variância, pelo programa SISVAR (FERREIRA, 2000). As variáveis que apresentaram variâncias homogêneas tiveram os tratamentos ava liados pelo teste F. Quando os resultados revelaram significância ao nível de 5\%, as médias dos fatores qualitativos (Pastejo) foram comparadas pelo teste de Tukey, ao nível de 5\%. Para os fatores quantitativos $(\mathrm{N})$, foram ajustadas equações de regressão polinomial (modelos linear e quadrático) entre as doses de $\mathrm{N}$ (variável categórica) com as variáveis avaliadas. 


\section{RESULTADOS E DISCUSSÃO}

A interação entre os sistemas de manejo e as doses de nitrogênio não foi significativa para nenhuma das variáveis (densidade do solo, macroporosidade, microporosidade e porosidade total) nos anos avaliados.

As maiores diferenças entre os tratamentos quanto à Ds ocorreram na fase 1 (Tabela 3). Verificou-se que ocorreu diferença significativa apenas na profundidade de $5-10 \mathrm{~cm}$ entre a área com e sem pastejo, apresentando a área pastejada maior média.

TABELA 3. Densidade do solo $\left(\mathrm{Mg} \mathrm{m}^{-3}\right)$ nas camadas de $0-5 ; 5-10$ e $10-15 \mathrm{~cm}$, nas fases experimentais, em respostas as condições com e sem pastejo, 2008, Guarapuava-PR. Soil density $\left(\mathrm{Mg} \mathrm{m}^{-3}\right)$ at the depths of 0-5, 5-10 and 10-15 cm and in different experiment stages, as responses to the conditions with and without grazing (Guarapuava - PR, Brazil, 2008).

\begin{tabular}{|c|c|c|c|c|c|c|}
\hline \multirow[b]{3}{*}{ Tratamentos Doses de N $\left(\mathrm{kg} \mathrm{ha}^{-1}\right)$} & \multicolumn{2}{|c|}{$\begin{array}{c}\text { Fase 1 } \\
\text { Após colheita do feijão }\end{array}$} & \multicolumn{2}{|c|}{$\begin{array}{c}\text { Fase } 2 \\
\text { Pastoreio } \\
\end{array}$} & \multicolumn{2}{|c|}{$\begin{array}{c}\text { Fase } 3 \\
\text { Após colheita do milho }\end{array}$} \\
\hline & \multicolumn{6}{|c|}{ Camada de 0 - 5 cm } \\
\hline & \multirow{2}{*}{$\begin{array}{c}\text { Com } \\
\text { Pastejo }\end{array}$} & \multirow{2}{*}{$\begin{array}{c}\text { Sem } \\
\text { Pastejo }\end{array}$} & \multirow{2}{*}{\multicolumn{2}{|c|}{ Com Pastejo Sem Pastejo }} & \multirow{2}{*}{\multicolumn{2}{|c|}{ Com Pastejo Sem Pastejo }} \\
\hline & & & & & & \\
\hline 0 & $1,09 \mathrm{a}$ & $1,11 \mathrm{a}$ & $1,06 \mathrm{a}$ & $1,04 \mathrm{a}$ & $0,89 \mathrm{a}$ & $0,97 \mathrm{a}$ \\
\hline 75 & $1,11 \mathrm{a}$ & $1,11 \mathrm{a}$ & $1,02 \mathrm{a}$ & $1,01 \mathrm{a}$ & $0,95 \mathrm{a}$ & $0,87 \mathrm{a}$ \\
\hline 150 & $1,09 \mathrm{a}$ & $1,05 \mathrm{a}$ & $1,04 \mathrm{a}$ & $1,03 \mathrm{a}$ & $0,96 \mathrm{a}$ & $0,97 \mathrm{a}$ \\
\hline 225 & $1,14 \mathrm{a}$ & $1,12 \mathrm{a}$ & $1,05 \mathrm{a}$ & $1,05 \mathrm{a}$ & 0,96 a & $0,92 \mathrm{a}$ \\
\hline \multirow[t]{3}{*}{ Médias } & 1,11 a & 1,10 a & $1,04 \mathrm{a}$ & $1,03 \mathrm{a}$ & 0,94 a & 0,94 a \\
\hline & \multicolumn{2}{|c|}{$\begin{array}{l}\text { Média geral }=1,10 ; \\
\mathrm{CV}(\%)=4,64 ; \mathrm{DMS}=0,05\end{array}$} & \multicolumn{2}{|c|}{$\begin{array}{l}\text { Média geral=1,03; } \\
\mathrm{CV}(\%)=5,65 ; \mathrm{DMS}=0,07\end{array}$} & \multicolumn{2}{|c|}{$\begin{array}{l}\text { Média geral=0,95; } \\
\text { CV }(\%)=12,73 ; \text { DMS }=0,15\end{array}$} \\
\hline & \multicolumn{6}{|c|}{ Camada de $5-10 \mathrm{~cm}$} \\
\hline 0 & $1,11 \mathrm{a}$ & $1,08 \mathrm{a}$ & $1,07 \mathrm{a}$ & $1,09 \mathrm{a}$ & $1,02 \mathrm{a}$ & $1,03 \mathrm{a}$ \\
\hline 75 & $1,13 \mathrm{a}$ & $1,10 \mathrm{a}$ & $1,05 \mathrm{a}$ & $1,08 \mathrm{a}$ & $0,99 \mathrm{a}$ & $0,97 \mathrm{a}$ \\
\hline 150 & $1,14 \mathrm{a}$ & $1,14 \mathrm{a}$ & $1,07 \mathrm{a}$ & $1,10 \mathrm{a}$ & $0,84 \mathrm{a}$ & $1,10 \mathrm{a}$ \\
\hline 225 & $1,17 \mathrm{a}$ & $1,08 \mathrm{~b}$ & $1,08 \mathrm{a}$ & $1,07 \mathrm{a}$ & $1,08 \mathrm{a}$ & $1,02 \mathrm{a}$ \\
\hline \multirow[t]{3}{*}{ Médias } & 1,14 a & $\mathbf{1 , 1 0} \mathrm{b}$ & $\mathbf{1 , 0 7} \mathbf{a}$ & $\mathbf{1 , 0 8} \mathbf{a}$ & 0,98 a & 1,02 a \\
\hline & \multicolumn{2}{|c|}{$\begin{array}{l}\text { Média geral=1,12; } \\
\mathrm{CV}(\%)=2,89 ; \mathrm{DMS}=0,06\end{array}$} & \multicolumn{2}{|c|}{$\begin{array}{l}\text { Média geral=1,07; } \\
\mathrm{CV}(\%)=3,55 ; \mathrm{DMS}=0,045\end{array}$} & \multicolumn{2}{|c|}{$\begin{array}{l}\text { Média geral }=1,00 ; \\
\mathrm{CV}(\%)=10,33 ; \mathrm{DMS}=0,22\end{array}$} \\
\hline & \multicolumn{6}{|c|}{ Camada de $10-15 \mathrm{~cm}$} \\
\hline 0 & $1,08 \mathrm{a}$ & $1,08 \mathrm{a}$ & $1,10 \mathrm{a}$ & $1,08 \mathrm{a}$ & $1,02 \mathrm{a}$ & $0,89 \mathrm{a}$ \\
\hline 75 & $1,15 \mathrm{a}$ & $1,13 \mathrm{a}$ & $1,08 \mathrm{a}$ & $1,01 \mathrm{a}$ & $0,97 \mathrm{a}$ & $0,97 \mathrm{a}$ \\
\hline 150 & $1,14 \mathrm{a}$ & $1,13 \mathrm{a}$ & $1,06 \mathrm{a}$ & $1,07 \mathrm{a}$ & $1,05 \mathrm{a}$ & $0,98 \mathrm{a}$ \\
\hline 225 & $1,11 \mathrm{a}$ & $1,14 \mathrm{a}$ & $1,09 \mathrm{a}$ & $1,07 \mathrm{a}$ & $1,02 \mathrm{a}$ & $1,02 \mathrm{a}$ \\
\hline \multirow[t]{2}{*}{ Médias } & $1,12 \mathrm{a}$ & 1,12 a & $1,08 \mathrm{a}$ & $1,06 \mathrm{a}$ & $1,01 \mathrm{a}$ & $0,97 \mathbf{a}$ \\
\hline & \multicolumn{2}{|c|}{$\begin{array}{l}\text { Média geral }=1,12 ; \\
\mathrm{CV}(\%)=4,12 ; \mathrm{DMS}=0,09\end{array}$} & \multicolumn{2}{|c|}{$\begin{array}{l}\text { Média geral=1,07; } \\
\mathrm{CV}(\%)=5,14 ; \mathrm{DMS}=0,08\end{array}$} & \multicolumn{2}{|c|}{$\begin{array}{l}\text { Média geral=0,99; } \\
\mathrm{CV}(\%)=8,58 ; \mathrm{DMS}=0,10\end{array}$} \\
\hline
\end{tabular}

Nota: Para cada fase, médias seguidas pela mesma letra na linha não diferem entre si, pelo teste de Tukey, ao nível de $5 \%$.

Nas fases 4 e 5 (Tabela 3), não ocorreu diferença significativa entre os tratamentos com e sem pastejo, nas três camadas estudadas. Os valores médios de Ds não atingiram valores limitantes de acordo com a classe textural do solo da região $\left(1,25-1,3 \mathrm{Mg} \mathrm{m}^{-3}\right)$ e, desta forma, não interferiram no desenvolvimento da cultura do milho, bem como da forragem, o que está de acordo com os resultados obtidos por BALBINOT JÚNIOR et al. (2011a, b).

Comparando as áreas com e sem pastejo, verificou-se que os valores de Ds, em geral, permaneceram dentro da faixa considerada pela literatura como não restritiva ao crescimento radicular. Outro fator que contribuiu diretamente foi a carga animal (Figura 3), com a média de 591; 726; 843 e $846 \mathrm{~kg} \mathrm{Pv}^{-1}$, nos tratamentos com $0 ; 75 ; 150$ e $225 \mathrm{~kg} \mathrm{~N} \mathrm{ha}^{-1}$, que foi adequada para o manejo implantado, não influenciando na produtividade da forragem e na consequente produtividade do milho, o que corrobora a desmistificação de que a presença de animais em áreas de lavoura é prejudicial à cultura subsequente. Segundo MOREIRA et al., (2012), os valores de Ds não aumentaram com a intensidade de pastejo. 
A comparação entre uma área com e sem pastejo indicou que os valores de densidade aumentaram com a presença dos animais, mas de forma a não comprometer a qualidade física do solo para a produção da cultura posterior à pastagem, e que ao longo do período de cultivo, existe um retorno à condição de densidade inicial, comprovando-se que a presença de animais em pastejo contínuo no inverno, quando a pastagem é bem manejada, não prejudica a Ds.

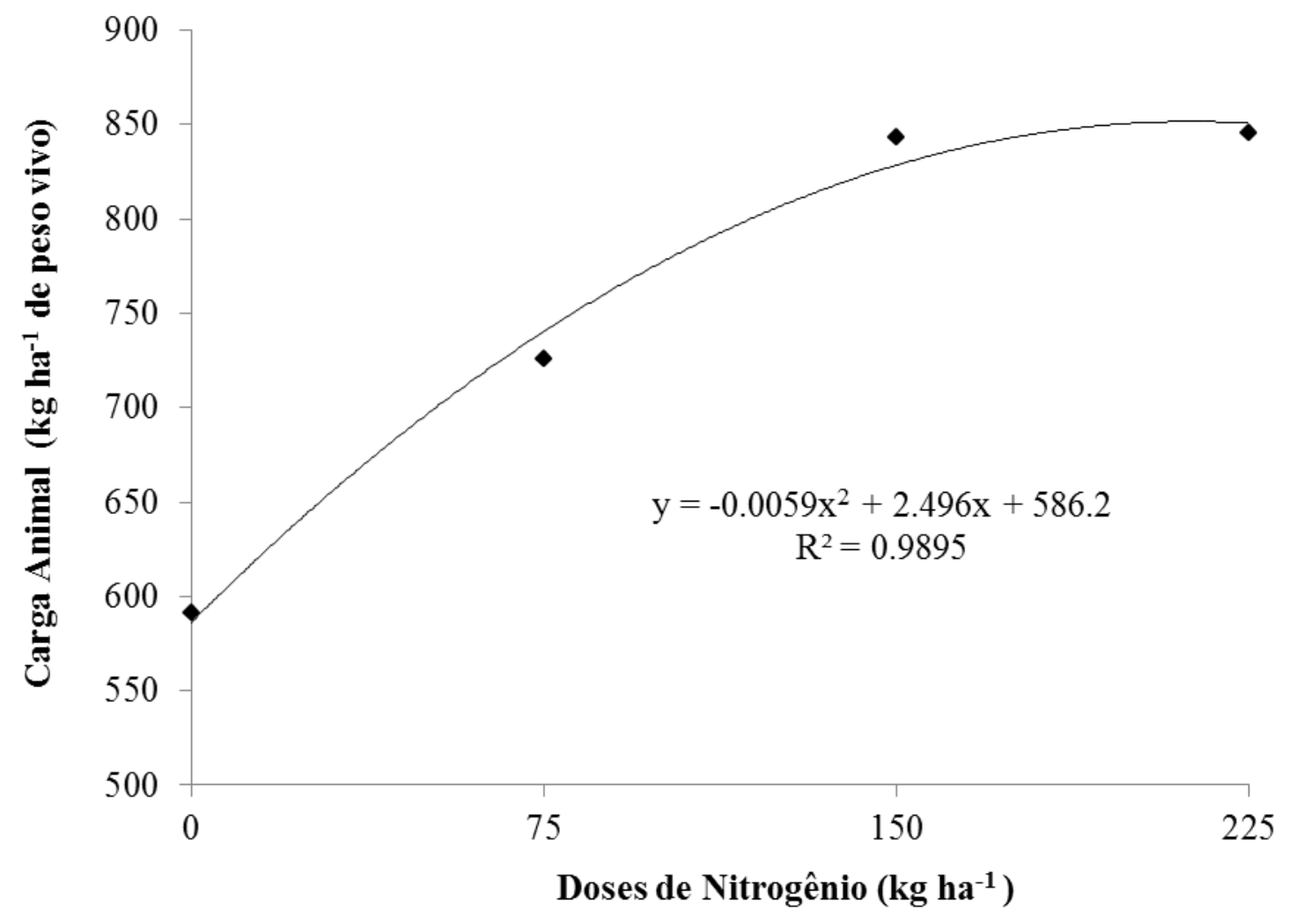

FIGURA 3. Carga animal ( $\mathrm{kg} \mathrm{ha}^{-1}$ de peso vivo-PV) em pastagem de aveia-branca (Avena sativa) e aze vém comum (Lolium multiflorum) de matrizes + cordeiros (período de 10-06 a 2809), em função das doses crescentes de N aplicadas. Guarapuava-PR, 2008. Animal Stocking rate $\left(\mathrm{kg} \mathrm{ha}^{-1}\right.$ ) in oat (Avena sativa) and ryegrass (Lolium multiflorum) grazing areas for lamb matrices (from June 10 to September 28) as a function of increasing doses of $\mathrm{N}$ applied (Gua rapuava - PR, Brazil, 2008).

Observou-se que os valores de macroporos, em todas as fases estudadas, não apresentaram diferenças significativas entre os tratamentos nas áreas com e sem pastejo. Verificou-se, ainda, que na fase 2 e 3, ocorreu visivelmente um aumento de macroporos, indicando que o manejo apropriado melhora as cond ições físicas do solo (Tabela 4).

No entanto, na fase 1, após a colheita do feijão, ocorreram valores de macroporos considerados restritivos ao desenvolvimento vegetal, principalmente na área com pastejo, ocorrendo valores na faixa de 0,07 a $0,09 \mathrm{~m}^{3} \mathrm{~m}^{-3}$ (ANDREOLLA et al., 2014).

Os macroporos estão relacionados com processos vitais para as plantas, devendo ser superiores a $0,10 \mathrm{~m}^{3} \mathrm{~m}^{-3}$ para permitir as trocas gasosas e o crescimento de raízes da maioria das culturas. No entanto, na integração lavoura-pecuária, principalmente no período de inverno, quando a umidade geralmente é elevada, podem ocorrer com o pisoteio animal alterações na densidade do solo e no volume de macroporos, no entanto essas alterações são reversíveis, devido a adição de matéria orgânica e ao sistema radicular das culturas. 
TABELA 4. Macroporosidade $\left(\mathrm{m}^{3} \mathrm{~m}^{-3}\right)$ nas camadas de $0-5 ; 5-10$ e $10-15 \mathrm{~cm}$, nas fases experimentais, em respostas às condições com e sem pastejo. 2008, GuarapuavaPR. Macroporosity $\left(\mathrm{m}^{3} \mathrm{~m}^{-3}\right)$ at the depths of 0-5; 5-10 and 10-15 and in different experiment stages, as responses to conditions with and without grazing (Gua rapuava - PR, Brazil, 2008).

\begin{tabular}{|c|c|c|c|c|c|c|}
\hline \multirow{3}{*}{$\begin{array}{l}\text { Tratamentos Doses } \\
\text { de } N\left(\mathrm{~kg} \mathrm{ha}^{-1}\right)\end{array}$} & \multicolumn{2}{|c|}{$\begin{array}{c}\text { Fase } 1 \\
\text { Após colheita do feijão }\end{array}$} & \multicolumn{2}{|c|}{$\begin{array}{c}\text { Fase } 2 \\
\text { Pastoreio }\end{array}$} & \multicolumn{2}{|c|}{$\begin{array}{c}\text { Fase } 3 \\
\text { Após colheita do milho }\end{array}$} \\
\hline & \multicolumn{6}{|c|}{ Camada de $0-5 \mathrm{~cm}$} \\
\hline & $\begin{array}{c}\text { Com } \\
\text { Pastejo }\end{array}$ & $\begin{array}{c}\text { Sem } \\
\text { Pastejo }\end{array}$ & Com Pastejo & Sem Pastejo & Com Pastejo & Sem Pastejo \\
\hline 0 & $0,09 \mathrm{a}$ & $0,11 \mathrm{a}$ & $0,17 \mathrm{a}$ & $0,12 \mathrm{a}$ & $0,21 \mathrm{a}$ & $0,18 \mathrm{a}$ \\
\hline 75 & $0,08 \mathrm{a}$ & $0,08 \mathrm{a}$ & $0,14 \mathrm{a}$ & $0,15 \mathrm{a}$ & $0,18 \mathrm{a}$ & $0,19 \mathrm{a}$ \\
\hline 150 & $0,11 \mathrm{a}$ & $0,12 \mathrm{a}$ & $0,15 \mathrm{a}$ & $0,16 \mathrm{a}$ & $0,21 \mathrm{a}$ & $0,16 \mathrm{a}$ \\
\hline 225 & $0,08 \mathrm{a}$ & $0,08 \mathrm{a}$ & $0,18 \mathrm{a}$ & $0,14 \mathrm{a}$ & $0,21 \mathrm{a}$ & $0,15 \mathrm{a}$ \\
\hline \multirow[t]{3}{*}{ Médias } & 0,09 a & 0,10 a & 0,16 a & 0,14 a & $0,20 \mathrm{a}$ & 0,17 b \\
\hline & \multicolumn{2}{|c|}{$\begin{array}{l}\text { Média geral }=0,10 ; \\
\mathrm{CV}(\%)=23,59 ; \mathrm{DMS}=0,03\end{array}$} & \multicolumn{2}{|c|}{$\begin{array}{l}\text { Média geral }=0,15 ; \\
\mathrm{CV}(\%)=15,22 ; \mathrm{DMS}=0,04\end{array}$} & \multicolumn{2}{|c|}{$\begin{array}{l}\text { Média geral }=0,19 ; \\
\mathrm{CV}(\%)=20,30 ; \mathrm{DMS}=0,05\end{array}$} \\
\hline & \multicolumn{6}{|c|}{ Camada de $5.10 \mathrm{~cm}$} \\
\hline 0 & $0,11 \mathrm{a}$ & $0,11 \mathrm{a}$ & $0,20 \mathrm{a}$ & $0,20 \mathrm{a}$ & $0,18 \mathrm{a}$ & $0,16 \mathrm{a}$ \\
\hline 75 & $0,07 \mathrm{a}$ & $0,11 \mathrm{a}$ & $0,15 \mathrm{a}$ & $0,17 \mathrm{a}$ & $0,16 \mathrm{a}$ & $0,18 \mathrm{a}$ \\
\hline 150 & $0,08 \mathrm{a}$ & $0,08 \mathrm{a}$ & $0,16 \mathrm{a}$ & $0,08 \mathrm{~b}$ & $0,17 \mathrm{a}$ & $0,18 \mathrm{a}$ \\
\hline 225 & $0,08 \mathrm{a}$ & $0,11 \mathrm{a}$ & $0,18 \mathrm{a}$ & $0,19 \mathrm{a}$ & $0,17 \mathrm{a}$ & $0,17 \mathrm{a}$ \\
\hline \multirow[t]{3}{*}{ Médias } & 0,08 a & 0,10 a & 0,17 a & 0,16 a & $0,17 a$ & 0,17 a \\
\hline & \multicolumn{2}{|c|}{$\begin{array}{l}\text { Média geral = } 0,09 ; \\
\mathrm{CV}(\%)=25,55 ; \mathrm{DMS}=0,02\end{array}$} & \multicolumn{2}{|c|}{$\begin{array}{l}\text { Média geral }=0,16 \\
\mathrm{CV}(\%)=15,91 ; \mathrm{DMS}=0,03\end{array}$} & \multicolumn{2}{|c|}{$\begin{array}{l}\text { Média geral }=0,17 ; \\
\mathrm{CV}(\%)=6,87 ; \mathrm{DMS}=0,02\end{array}$} \\
\hline & \multicolumn{6}{|c|}{ Camada de $10-15 \mathrm{~cm}$} \\
\hline 0 & $0,10 \mathrm{a}$ & 0,11 a & $0,18 \mathrm{a}$ & $0,19 \mathrm{a}$ & $0,19 \mathrm{a}$ & $0,20 \mathrm{a}$ \\
\hline 75 & $0,07 \mathrm{a}$ & $0,06 \mathbf{a}$ & $0,20 \mathrm{a}$ & $0,22 \mathrm{a}$ & $0,16 \mathrm{a}$ & $0,18 \mathrm{~b}$ \\
\hline 150 & $0,08 \mathrm{a}$ & 0,08 a & $0,15 \mathrm{a}$ & $0,14 \mathrm{a}$ & $0,15 \mathrm{a}$ & $0,16 \mathrm{a}$ \\
\hline 225 & $0,09 \mathrm{~b}$ & 0,11 a & $0,15 \mathrm{a}$ & $0,18 \mathrm{a}$ & $0,15 \mathrm{a}$ & $0,17 \mathrm{~b}$ \\
\hline \multirow[t]{2}{*}{ Médias } & 0,08 a & 0,09 a & 0,17 a & 0,18 a & $0,16 \mathrm{~b}$ & 0,18 a \\
\hline & \multicolumn{2}{|c|}{$\begin{array}{l}\text { Média geral }=0,09 ; \\
\mathrm{CV}(\%)=19,77 ; \mathrm{DMS}=0,02\end{array}$} & \multicolumn{2}{|c|}{$\begin{array}{l}\text { Média geral }=0,18 ; \\
\mathrm{CV}(\%)=15,53 ; \mathrm{DMS}=0,05\end{array}$} & \multicolumn{2}{|c|}{$\begin{array}{l}\text { Média geral }=0,17 \\
\mathrm{CV}(\%)=3,93 ; \text { DMS }=0,01\end{array}$} \\
\hline
\end{tabular}

Nota: Para cada fase, médias seguidas pela mesma letra na linha não diferem entre si, pelo teste de Tukey, ao nível de 5\%.

Já na fase 3, a macroporosidade observada nos diferentes tratamentos foi igual ou superior ao limite mínimo de $0,10 \mathrm{~m}^{3} \mathrm{~m}^{-3}$, ideal para que ocorra a adequada difusão de oxigênio no solo, para o bom desenvolvimento das plantas. SANTOS et al. (2011), estudando sistemas integrados e consorciados, verificaram valores semelhantes para consórcio de $U$. brizantha em consórcio com milho.

Após a colheita do feijão (Fase 1), reduziu-se o volume de macroporos; no entanto, percebeuse que os macroporos aumentaram consideravelmente após o pastejo e após a colheita do milho (fases 4 e 5). Isto está de acordo com ANDREOLLA et al. (2014) e BALBINOT JÚNIOR et al. (2011a), que uma das mais prováveis razões para o aumento de macroporos é o efeito das raízes da cultura do milho, assim como as das pastagens. As raízes do milho, ao penetrarem, comprimem as partículas do solo, e com a morte e a decomposição formam os bioporos, que contribuem para o aumento da macroporosidade, os quais relatam que o sistema radicular de gramíneas possibilita uma melhora na estrutura física do solo, pelo aumento da porosidade total e pelo acréscimo de matéria orgânica ao solo, melhorando a estrutura e a estabilidade dos agregados, principalmente da superfície do solo.

Na Tabela 5, são apresentados os dados de microporosidade, para as fases 3, 4 e 5. 
TABELA 5. Microporosidade $\left(\mathrm{m}^{3} \mathrm{~m}^{-3}\right)$ nas camadas de $0-5 ; 5-10$ e $10-15 \mathrm{~cm}$, nas fases experimentais, em respostas às condições com e sem pastejo. 2008, Guarapuava-PR. Microporosity $\left(\mathrm{m}^{3} \mathrm{~m}^{-3}\right)$ at the depths of 0-5; 5-10 and 10-15 and in different experiment stages, as responses to conditions with and without grazing, (Gua rapuava - PR, Brazil, 2008).

\begin{tabular}{|c|c|c|c|c|c|c|}
\hline \multirow{3}{*}{$\begin{array}{l}\text { Tratamentos Doses } \\
\text { de N }\left(\mathrm{kg} \mathrm{ha}^{-1}\right)\end{array}$} & \multicolumn{2}{|c|}{$\begin{array}{c}\text { Fase } 1 \\
\text { Após colheita do feijão }\end{array}$} & \multicolumn{2}{|c|}{$\begin{array}{c}\text { Fase } 2 \\
\text { Pastoreio }\end{array}$} & \multicolumn{2}{|c|}{$\begin{array}{c}\text { Fase } 3 \\
\text { Após colheita do milho }\end{array}$} \\
\hline & \multicolumn{6}{|c|}{ Camada de 0 - $5 \mathrm{~cm}$} \\
\hline & $\begin{array}{c}\text { Com } \\
\text { Pastejo }\end{array}$ & $\begin{array}{c}\text { Sem } \\
\text { Pastejo }\end{array}$ & Com Pastejo & Sem Pastejo & Com Pastejo & $\begin{array}{c}\text { Sem } \\
\text { Pastejo }\end{array}$ \\
\hline 0 & $0,52 \mathrm{a}$ & $0,50 \mathrm{a}$ & $0,44 \mathrm{a}$ & $0,44 \mathrm{a}$ & $0,47 \mathrm{a}$ & $0,48 \mathrm{a}$ \\
\hline 75 & $0,48 \mathrm{a}$ & $0,51 \mathrm{a}$ & $0,47 \mathrm{a}$ & $0,47 \mathrm{a}$ & $0,44 \mathrm{a}$ & $0,48 \mathrm{a}$ \\
\hline 150 & $0,46 \mathrm{a}$ & $0,50 \mathrm{a}$ & $0,43 \mathrm{a}$ & $0,45 \mathrm{a}$ & $0,41 \mathrm{a}$ & $0,48 \mathrm{a}$ \\
\hline 225 & $0,49 \mathrm{a}$ & $0,46 \mathrm{a}$ & $0,44 \mathrm{a}$ & $0,44 \mathrm{a}$ & $0,40 \mathrm{a}$ & $0,48 \mathrm{a}$ \\
\hline \multirow{3}{*}{ Médias } & $0,49 \mathrm{a}$ & 0,49 a & $0,44 a$ & 0,45 a & $\mathbf{0 , 4 3}$ b & 0,48 a \\
\hline & $\begin{array}{l}\text { Média geral }=0,49 ; \\
\mathrm{CV}(\%)=4,36 ; \mathrm{DMS}=0,03\end{array}$ & & $\begin{array}{l}\text { Média geral }=0,45 ; \\
\text { CV }(\%)=5,59 ; \mathrm{DMS}=0,04\end{array}$ & $\begin{array}{l}\text { Média } \\
\text { CV \%) }\end{array}$ & $\begin{array}{l}\text { geral }=0,46 ; \\
=7,85 ; \text { DMS }=0,05\end{array}$ & \\
\hline & \multicolumn{6}{|c|}{ Camada de $5-10 \mathrm{~cm}$} \\
\hline 0 & $0,48 \mathrm{a}$ & $0,52 \mathrm{a}$ & $0,43 \mathrm{a}$ & $0,42 \mathrm{a}$ & $0,45 \mathrm{a}$ & $0,48 \mathrm{a}$ \\
\hline 75 & $0,49 \mathrm{a}$ & $0,47 \mathrm{a}$ & $0,42 \mathrm{a}$ & $0,44 \mathrm{a}$ & $0,45 \mathrm{a}$ & $0,45 \mathrm{a}$ \\
\hline 150 & $0,48 \mathrm{a}$ & $0,40 \mathrm{~b}$ & $0,43 \mathrm{a}$ & $0,42 \mathrm{a}$ & $0,51 \mathrm{a}$ & $0,32 \mathbf{b}$ \\
\hline 225 & $0,48 \mathrm{a}$ & $0,50 \mathrm{a}$ & $0,42 \mathrm{a}$ & $0,42 \mathrm{a}$ & $0,44 \mathrm{a}$ & $0,46 \mathrm{a}$ \\
\hline \multirow[t]{3}{*}{ Médias } & 0,48 a & $\mathbf{0 , 4 7} \mathbf{a}$ & $0,42 \mathrm{a}$ & 0,43 a & 0,46 a & $0,44 \mathbf{a}$ \\
\hline & $\begin{array}{l}\text { Média geral }=0,48 ; \\
\mathrm{CV}(\%)=4,13 ; \mathrm{DMS}=0,02\end{array}$ & & $\begin{array}{l}\text { Média geral }=0,43 ; \\
\mathrm{CV}(\%)=3,32 ; \mathrm{DMS}=0,03\end{array}$ & $\begin{array}{l}\text { Média } \\
\text { CV(\%) }\end{array}$ & $\begin{array}{l}\text { geral }=0,45 ; \\
=27,11 ; \mathrm{DMS}=0,02\end{array}$ & \\
\hline & \multicolumn{6}{|c|}{ Camada de $10-15 \mathrm{~cm}$} \\
\hline 0 & $0,43 \mathrm{~b}$ & $0,48 \mathrm{a}$ & $0,43 \mathrm{a}$ & $0,43 \mathrm{a}$ & $0,46 \mathrm{a}$ & $0,46 \mathrm{a}$ \\
\hline 75 & $0,51 \mathrm{a}$ & $0,52 \mathrm{a}$ & $0,42 \mathrm{a}$ & $0,44 \mathrm{a}$ & $0,48 \mathrm{a}$ & $0,44 \mathrm{a}$ \\
\hline 150 & $0,48 \mathrm{a}$ & $0,48 \mathrm{a}$ & $0,43 \mathrm{a}$ & $0,41 \mathrm{a}$ & $0,47 \mathrm{a}$ & $0,47 \mathrm{a}$ \\
\hline 225 & $0,48 \mathrm{a}$ & $0,47 \mathrm{a}$ & $0,42 \mathrm{a}$ & $0,42 \mathrm{a}$ & $0,50^{\mathrm{a}}$ & $0,46 \mathrm{a}$ \\
\hline Médias & 0,48 a & 0,49 a & 0,42 a & $\mathbf{0 , 4 2} \mathbf{a}$ & 0,48 a & 0,46 a \\
\hline & $\begin{array}{l}\text { Média geral }=0,48 ; \\
\mathrm{CV}(\%)=2,97 ; \mathrm{DMS}=0,04\end{array}$ & & $\begin{array}{l}\text { Média geral }=0,43 ; \\
\text { CV }(\%)=3,03 ; \mathrm{DMS}=0,02\end{array}$ & $\begin{array}{l}\text { Média } \\
\text { CV }(\%\end{array}$ & $\begin{array}{l}\text { geral }=0,47 \\
=7,23 ; \mathrm{DMS}=0,04\end{array}$ & \\
\hline
\end{tabular}

Nas camadas de 0 - 5 e 10 - $15 \mathrm{~cm}$, em todas as fases estudadas, os valores médios de microporos não diferiram nas áreas com e sem pastejo. Porém, comparando-se as fases 3 e 4, notase que ocorreu uma melhora na qualidade do solo na fase 2 principalmente, devido ao aporte de material orgânico através de resíduos vegetais e animais, além da ação benéfica das raízes das plantas e da proteção oferecida à superfície do solo, favorecendo a reestruturação do mesmo, e fazendo com que o volume de macroporos seja aumentado (Tabela 4). SILVA et al. (2011) encontraram resultados semelhantes utilizando sistema de manejo semelhante.

Para SANDINI et al. (2011) e SILVA et al. (2011), os efeitos benéficos das gramíneas na formação e na estabilização dos agregados do solo são devidos à alta densidade de raízes, que promove a aproximação das partículas pela constante absorção de água do perfil do solo, às periódicas renovações do sistema radicular e à uniforme distribuição de exsudatos no solo, que estimulam a atividade microbiana, cujos subprodutos atuam na formação e na estabilização dos agregados.

Em relação à Pt do solo (Tabela 6), verificou-se que, na camada de $5-10 \mathrm{~cm}$, ocorre diferença significativa entre as áreas com e sem pastejo no tratamento com dose de $150 \mathrm{~kg} \mathrm{ha}^{-1}$, evidenciando que a área sem pastejo apresentou menores médias, devido ao menor volume de microporos e macroporos encontrados neste tratamento (Tabelas 5 e 4). Nas camadas de $0-5 \mathrm{~cm}$, verificou-se diferenças significativas entre as áreas com e sem pastejo na dose de 150 e $225 \mathrm{~kg} \mathrm{ha}^{-1}$ e na camada de 10 - $15 \mathrm{~cm}$, ocorreu para as doses de 0 e $225 \mathrm{~kg} \mathrm{ha}^{-1}$ após a colheita do feijão (Fase 1).

Em geral, não ocorre alterações expressivas nos valores de porosidade total por parte do pastejo em diferentes doses de N, o que está de acordo com ANDREOLLA et al. (2014). MOREIRA et al. (2012) e BALBINOT JUNIOR et al. (2011a,b), estudando pastagens sob plantio 
direto, concluíram não haver evidências de que o pisoteio tenha interferido negativamente nos atributos físicos do solo,e desta forma as raízes das culturas subsequentes conseguem melhorar a qualidade do solo, mesmo tendo o pisoteio animal.

TABELA 6. Porosidade total $\left(\mathrm{m}^{3} \mathrm{~m}^{-3}\right)$ nas camadas de 0-5; 5-10 e 10-15 cm, nas fases experimentais, em respostas as condições com e sem pastejo. 2008, GuarapuavaPR. Total porosity $\left(\mathrm{m}^{3} \mathrm{~m}^{-3}\right)$ at the depths of 0-5, 5-10 and 10-15 and in diffe rent experiment stages, as responses to conditions with and without grazing (Gua ra puava-PR, Brazil, 2008).

\begin{tabular}{|c|c|c|c|c|c|c|}
\hline \multirow{3}{*}{$\begin{array}{c}\text { Tratamentos } \\
\text { Doses de N (kg } \\
\left.\text { ha }^{-1}\right)\end{array}$} & \multicolumn{2}{|c|}{$\begin{array}{c}\text { Fase 1 } \\
\text { Após colheita do feijão }\end{array}$} & \multicolumn{2}{|c|}{$\begin{array}{c}\text { Fase 2 } \\
\text { Pastoreio }\end{array}$} & \multicolumn{2}{|c|}{$\begin{array}{c}\text { Fase 3 } \\
\text { Após colheita do milho }\end{array}$} \\
\hline & \multicolumn{6}{|c|}{ Camada de $0-5 \mathrm{~cm}$} \\
\hline & $\begin{array}{c}\text { Com } \\
\text { Pastejo }\end{array}$ & $\begin{array}{c}\text { Sem } \\
\text { Pastejo }\end{array}$ & Com Pastejo & Sem Pastejo & Com Pastejo & $\begin{array}{c}\text { Sem } \\
\text { Pastejo }\end{array}$ \\
\hline 0 & $0,61 \mathrm{a}$ & $0,62 \mathrm{a}$ & $0,61 \mathrm{a}$ & $0,56 \mathrm{a}$ & $0,68 \mathrm{a}$ & $0,66 \mathrm{a}$ \\
\hline 75 & $0,56 \mathrm{a}$ & $0,58 \mathrm{a}$ & $0,61 \mathrm{a}$ & $0,62 \mathrm{a}$ & $0,62 \mathrm{a}$ & $0,67 \mathrm{a}$ \\
\hline 150 & $0,57 \mathrm{~b}$ & $0,61 \mathrm{a}$ & $0,58 \mathrm{a}$ & $0,61 \mathrm{a}$ & $0,62 \mathrm{a}$ & $0,64 a$ \\
\hline 225 & $0,58 \mathrm{a}$ & $0,54 \mathrm{~b}$ & $0,62 \mathrm{a}$ & $0,58 \mathrm{a}$ & $0,61 \mathrm{a}$ & $0,63 \mathrm{a}$ \\
\hline \multirow[t]{3}{*}{ Médias } & $\mathbf{0 , 5 8} \mathrm{a}$ & 0,59 a & $0,60 \mathrm{a}$ & $\mathbf{0 , 5 9}$ a & $0,63 \mathrm{a}$ & $0,65 \mathrm{a}$ \\
\hline & \multicolumn{2}{|c|}{$\begin{array}{l}\text { Média geral }=0,58 \\
\mathrm{CV}(\%)=3,48 ; \mathrm{DMS}=0,02\end{array}$} & \multicolumn{2}{|c|}{$\begin{array}{l}\text { Média geral }=0,60 \\
\mathrm{CV}(\%)=5,55, \mathrm{DMS}=0,05\end{array}$} & \multicolumn{2}{|c|}{$\begin{array}{l}\text { Média geral }=0,64 \\
\mathrm{CV}(\%)=5,54 ; \mathrm{DMS}=0,05\end{array}$} \\
\hline & \multicolumn{6}{|c|}{ Camada de $5-10 \mathrm{~cm}$} \\
\hline 0 & $0,59 \mathrm{~b}$ & $0,63 \mathrm{a}$ & $0,63 \mathrm{a}$ & $0,62 \mathrm{a}$ & $0,63 \mathrm{a}$ & $0,64 \mathrm{a}$ \\
\hline 75 & $0,56 \mathrm{~b}$ & $0,59 \mathrm{a}$ & $0,57 \mathrm{a}$ & $0,61 \mathrm{a}$ & $0,61 \mathrm{a}$ & $0,63 \mathrm{a}$ \\
\hline 150 & $0,56 \mathrm{a}$ & $0,48 \mathrm{~b}$ & $0,58 \mathrm{a}$ & $0,50 \mathrm{~b}$ & $0,68 \mathrm{a}$ & $0,50 \mathrm{~b}$ \\
\hline 225 & $0,57 \mathrm{~b}$ & $0,60 \mathrm{a}$ & $0,60 \mathrm{a}$ & $0,61 \mathrm{a}$ & $0,61 \mathrm{a}$ & $0,63 \mathrm{a}$ \\
\hline \multirow[t]{3}{*}{ Médias } & $\mathbf{0 , 5 7} \mathbf{a}$ & 0,57 a & 0,59 a & $\mathbf{0 , 5 8}$ a & $0,63 \mathrm{a}$ & $0,61 \mathrm{a}$ \\
\hline & \multicolumn{2}{|c|}{$\begin{array}{l}\text { Média geral }=0,57 \\
\mathrm{CV}(\%)=2,08 ; \mathrm{DMS}=0,02\end{array}$} & \multicolumn{2}{|c|}{$\begin{array}{l}\text { Média geral }=0,58 ; \\
\text { CV }(\%)=4,90 ; \text { DMS }=0,04\end{array}$} & \multicolumn{2}{|c|}{$\begin{array}{l}\text { Média geral }=0,62 ; \\
\mathrm{CV}(\%)=15,13 ; \mathrm{DMS}=0,15\end{array}$} \\
\hline & \multicolumn{6}{|c|}{ Camada de $10-15 \mathrm{~cm}$} \\
\hline 0 & $0,53 \mathrm{~b}$ & $0,59 \mathrm{a}$ & $0,61 \mathrm{a}$ & $0,62 \mathrm{a}$ & $0,65 \mathrm{a}$ & $0,66 \mathrm{a}$ \\
\hline 75 & $0,59 \mathrm{a}$ & $0,58 \mathrm{a}$ & $0,62 \mathrm{a}$ & $0,66 \mathrm{a}$ & $0,64 \mathrm{a}$ & $0,62 \mathrm{a}$ \\
\hline 150 & $0,56 \mathrm{a}$ & $0,56 \mathrm{a}$ & $0,58 \mathrm{a}$ & $0,55 \mathrm{a}$ & $0,62 \mathrm{a}$ & $0,63 \mathrm{a}$ \\
\hline 225 & $0,57 \mathrm{a}$ & $0,58 \mathrm{a}$ & $0,57 \mathrm{a}$ & $0,60 \mathrm{a}$ & $0,65 \mathrm{a}$ & $0,63 \mathrm{a}$ \\
\hline \multirow[t]{2}{*}{ Médias } & $\mathbf{0 , 5 6} \mathrm{b}$ & $\mathbf{0 , 5 8}$ a & 0,60 a & $0,61 \mathrm{a}$ & $0,64 \mathbf{a}$ & $0,63 \mathrm{a}$ \\
\hline & \multicolumn{2}{|c|}{$\begin{array}{l}\text { Média geral }=0,57 \\
\mathrm{CV}(\%)=3,21 ; \mathrm{DMS}=0,04\end{array}$} & \multicolumn{2}{|c|}{$\begin{array}{l}\text { Média geral }=0,60 ; \\
\mathrm{CV}(\%)=2,99 ; \mathrm{DMS}=0,04\end{array}$} & \multicolumn{2}{|c|}{$\begin{array}{l}\text { Média geral }=0,64 ; \\
\mathrm{CV}(\%)=, 3,50 ; \mathrm{DMS}=0,03\end{array}$} \\
\hline
\end{tabular}

Os valores médios encontrados de produtividades do milho na área com pastejo foram de $10.220 \mathrm{~kg} \mathrm{ha}^{-1}$, e na área sem pastejo, de $9.636 \mathrm{~kg} \mathrm{ha}^{-1}$, demonstrando que houve efeito residual do $\mathrm{N}$ aplicado na pastagem em função do comportamento da cultura do milho. A produtividade de grãos de milho apresentou resposta em um modelo quadrático (Figura 4). 


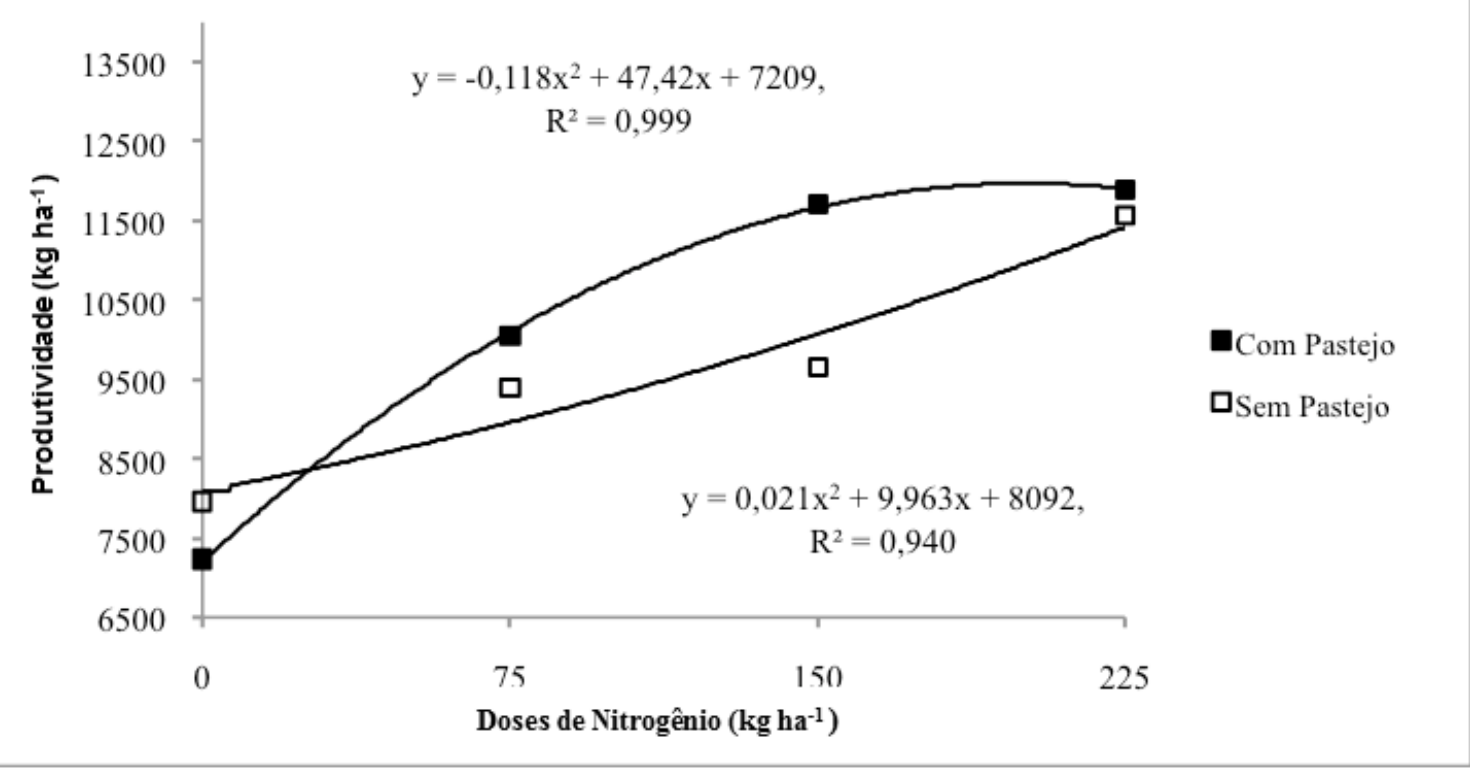

FIGURA 4. Produtividade de grãos do milho $\left(\mathrm{kg} \mathrm{ha}^{-1}\right)$, na presença e ausência de pastejo, frente às doses de aplicação de $\mathrm{N}$ na pastagem. Guarapuava-PR, 2008. Corn grain yields (kg $\mathrm{ha}^{-1}$ ) in the presence and absence of grazing, as result of nitrogen doses (Guarapuava - PR, Brazil, 2008).

Com relação à produtividade, observou-se que, na área pastejada, ocorreram as maiores produtividades, com exceção do tratamento sem aplicação de $\mathrm{N}$, que apresentou menor produtividade. Segundo YAGUSHI (2013), a produtividade do Paraná, neste período foi de $5.338 \mathrm{~kg}$ $\mathrm{ha}^{-1}$, enquanto nas áreas com e sem pastejo ocorreu a maior produtividade, indicando que o sistema de integração lavoura-pecuária pode direcionar o uso sustentável do solo e das pastagens.

Resultados semelhantes foram obtidos por BALBINOT JÚNIOR et al. (2011b), que observaram efeito residual do $\mathrm{N}$ aplicado na pastagem associado com o efeito da ciclagem de nutrientes sobre a cultura do milho. À medida que aumentam as doses de $\mathrm{N}$ aplicada no inverno ocorre aumento da produtividade de grãos na área pastejada, sendo superiores às áreas sem pastejo.

$\mathrm{O}$ pastejo pode ter favorecido a ciclagem mais rápida do $\mathrm{N}$ aplicado, estimulando a absorção de $\mathrm{N}$ pelas plantas, através do processo de mineralização e de imobilizações de $\mathrm{N}$, resultante da deposição de urina e fezes que ficam na superfície do solo, possibilitando, desta forma, maior aproveitamento do nutriente aplicado, quando comparado às áreas que não receberam pastejo. A presença de animais na área não ocasionou efeito suficiente de compactação superficial que pudesse limitar o desenvolvimento das plantas (SANDINI et al., 2011).

ANGHINONI et al. (2011) e SILVA et al. (2011) relataram que, no sistema ILP, além do não revolvimento do solo, há maior deposição de resíduos vegetais pela rotação de cultura, ocorrendo intensa renovação de massa radicular das pastagens, o que resulta em mais exsudatos radiculares, temperatura menos variável e aumento da matéria orgânica do solo, que favorece um ambiente ótimo para o desenvolvimento da biota do solo. A diversidade de invertebrados no solo desempenha papel importante nos ciclos biogeoquímicos, realizando a decomposição, a ciclagem de nutrientes, a mineralização e a modificação da estrutura do solo. 


\section{CONCLUSÕES}

O pastejo com ovinos, em sistema de lotação contínua, com controle da taxa de lotação animal e manutenção da massa de forragem consorciada com aveia e azevém, adubado com nitrogênio, não alterou a densidade, a macroporosidade, a microporosidade e a porosidade total no Latossolo Bruno.

Em um sistema de integração lavoura-pecuária, o pastejo nas áreas que receberam adubação nitrogenada na pastagem, não prejudicou a produtividade da cultura do milho.

A adubação nitrogenada da pastagem de inverno, igual ou superior a $150 \mathrm{~kg} \mathrm{~N} \mathrm{ha}^{-1}$, garante elevada produtividade da cultura do milho na ausência da aplicação de $\mathrm{N}$.

\section{REFERÊNCIAS}

ANDREOLLA, V. R. M.; BONINI, A. K. DEISS, L. ; SANDINI, I. E. Soil physical attributes in integrated bean and sheep system under nitrogen levels. Revista Ciência Agronômica, Fortaleza, v.45, n.5, p. 922-930, 2014.

ANGHINONI, I.; MARTINS, A. P.; ASSMANN, J. M. COSTA, S. E.; CARVALHO, P.C. Ciclagem de nutrientes em integração lavoura- pecuária. In: ENCONTRO DE INTEGRAÇÃO LAVOURA - PECUÁRIA NO SUL DO BRASIL, 3., 2011, Pato Branco. Trabalhos apresentados...

BALBINOT JÚNIOR., A. A.; MORAES, A.; PELISSARI, A.; VEIGA, M. da; DIECKOW, J. Estratégias de uso do solo no inverno e seu efeito no milho cultivado em sucessão. Revista Brasileira de Agrociência, Pelotas, v.17, n.1, p.94-107, 2011a.

BALBINOT JÚNIOR, A. A; MORAES, A.; VEIGA, M.; PELISSARI, A.; MAFRA, Á. L.; PICCOLLA, C. D. Winter pasture and cover crops and their effects on soil and summer grain crops. Pesquisa Agropecuá ria B rasileira, Brasília, DF, v.46, n.10, p.1357-1363, 2011 b.

BALBINOT JÚNIOR, A. A; VEIGA, M.; VOGT, G. A.; SPAGNOLlO, E. Atributos de solo e produtividade de feijão após diferentes formas de uso do solo no inverno, no quinto ano de experimentação. Ciência Rural, Santa Maria, v.42, n.3, p.401-406, 2012.

CARVALHO, P.C.F.; RIBEIRO FILHO, H.M.N.; POLI, C.H.E.C. MORAES, A.; DELAGARDE, R. Importância da estrutura da pastagem na ingestão de dietas pelo animal em pastejo. In: REUNIÃO ANUAL DA SOCIEDADE BRASILEIRA DE ZOOTECNIA, 38., 2001, Piracicaba. Anais... Piracicaba: Fundação de Estudos Agrários Luiz de Queiroz, 2001. p.853-871.v

CONTE, O.; Flores, J. P. C.; CASSOL, L. C.; ANGHINONI, I.; CARVAlHO, P. C. F.; LEVIEN, R.; WESP, C. L. Evolução de atributos físicos de solo em sistema de integração lavourapecuária. Pesquisa Agropecuária B rasileira, Brasília, DF, v.46, n.10, p.1301-1309, 2011.

EMBRAPA - EMPRESA BRASILEIRA DE PESQUISA AGROPECUÁRIA. Centro Nacional de Pesquisa de Solos. Manual de análise de solo. 2. ed. rev. atual. Rio de Janeiro: Centro Nacional de Pesquisa de Solos, 1997. 212p.

EMBRAPA - EMPRESA BRASILEIRA DE PESQUISA AGROPECUÁRIA. Sistema brasileiro de classificação de solo. 3. ed. Rio de Janeiro: Centro Nacional de Pesquisa de Solos, 2013. 353p.

FERREIRA, D. F. Manual do sistema SISVAR para análises estatísticas. Lavras: UFLA, 2000. 63p.

FREITAS, T. M. S. Dinâmica da produção de forragem, comportamento ingestivo e produção de ovelhas Ile de France em pastagem de azevém anual (Lolium multiflorum Lam.) em resposta a doses de nitrogênio. 2003. 114f. Dissertação (Mestrado) -Faculdade de Agronomia, Universidade Federal do Rio Grande do Sul, Porto Alegre, 2003. 
MOOT, G. O; LUCAS, H. L. The design conduct and interpretation of grazing trials on cultivated and improved pastures. In: INTERNATIONAL GRASSLAND CONGRESS, 6., 1952, Penns ylvania State College. Proceedings... p.1380-1395.

MOREIRA, W. H.; BETIOLI JÚNIOR, E.; PETEAM, L. P.; TORMENA, C. A.; ALVES, S. J. F. Atributos físicos de um Latos solo Vermelho Distroférrico em sistema de integração lavourapecuária. Revista Brasileira de Ciência do Solo, Viçosa, MG, v.36, n.2, p.389-400, 2012.

PETEAN, L. P.; TORMENA, C. A.; FIDALSKI, J.; ALVES, S. J. Altura de pastejo de aveia e azevém e qualidade física de um Latossolo Vermelho distroférrico sob integração lavoura-pecuária. Semina: Ciências Agrárias, Londrina, v.30, p.1009-1016, 2009.

PETEAN, L.P.; TORMENA, C.A.; ALVES, S.J. Intervalo hídrico ótimo de um Latossolo Vermelho distroférrico sob plantio direto em sistema de integração lavoura-pecuária. Revista Brasileira de Ciência do Solo, Viçosa, MG, v.34, n.5, p.1515-1526, 2010.

ROLIM, G. S.; SENTELHAS, P.C.; BARBIERI, V. Planilhas no ambiente EXCEL para os cálculos de balanços hídricos: normal, sequencial, de cultura e de produtividade real e potencial. Revista Brasileira de Agrometeorologia, Santa Maria, v.6, p.133-137, 1998.

ROZANE, D. E.; CENTURION, J. F.; ROMUALDO, L. M.; TANIGUCHI, C. A. K.; TRABUCO, M.; ALVES, A. U. Estoque de carbono e estabilidade de agregados de um Latossolo vermelho distrófico, sob diferentes manejos. Bioscience Journal, Uberlândia, v.26, n. 1, p. 24-32, 2010.

SANDINI, I. E.; MORAES, A.; PELISSARI, A.; NEUMANN, M.; FALBO, M. K.; NOVAKOWISKI, J. H. Efeito residual do nitrogênio na cultura do milho no sistema de prod ução integração lavoura-pecuária. Ciências Rural. Santa Maria, v.41, n.8, p.1315-1322, 2011.

SANTOS, G. G.; MARCHÃO, R. L.; SILVA, E. M. da, SILVEIRA, P. M. da; BECQUER, T. Qualidade física do solo sob sistemas de integração lavoura-pecuária. Pesquisa Agropecuária Brasileira, Brasília, DF, v.46, n.10, p.1339-1348, 2011.

SILVA, R. F.; GUIMARÃES, M. de F.; AQUINO, A. M. de; MERCANTE, F. M.. Análise conjunta de atributos físicos e biológicos do solo sob sistema de integração lavoura-pecuaria Pesquisa Agropecuária Brasileira, Brasília, DF, v.46, n.10, p.1277-1283, 2011.

THORNTHWAITE, C. W.; MATHER, J. R. The water balance. Publications in Climatology, New Jersey: Drexel Institute of Technology, 1955. 104p.

YAGUSHI, J. T. Milho paranaense - safra 2013/14. Disponível em: <http:/ www.agricultura.pr.gov.br/arquivos/file/deral/.../milho_analise.pdf $>$. Acesso em:10/11/2014. 